\title{
Antimicrobial Activity of Endangered Medicinal Plant Gloriosa Superba L.
}

\author{
Dr. K. Geetha ${ }^{1}$, A. P. Gowsalyadevi ${ }^{2}$ \\ Department of Botany with Specialization in Plant Biotechnology, The Standard fireworks Rajaratnam College for Women, Sivakasi
}

\begin{abstract}
Indian subcontinent is praised with most varied and diverse soil and climate conditions suitable for the growth of various plant species and endowed with rich wealth of medicinal plants.Gloriosa superba L. has been a source of medicine right from ancient time. Medicinal plants have bioactive compounds which are used for curing of various human diseases and also play an important role in healing. Screening of antimicrobial activity of Gloriosa superba L. in the leaves was studied. The leaves of the selected medicinal plants were washed, air dried and then powdered. The main objective was to check the presence or absence of the antimicrobial activity of leaves of the selected medicinal plant. In the present study, preliminary antimicrobial activity of Gloriosa superba L.(leaves, stem and flower) exhibited high degrees of antibacterial activity against tested pathogenic microorganisms Bacillus sps., Escherichia coli and Pseudomonas aeruginosa, when studied by the disc diffusion method. The acetone extract of Gloriosa superba L. was found to be effective against all tested microorganisms with the inhibition zone ranging with an average of $1.0-2.9$ mm. When the result was compared with standard antibiotic, streptomycin, a moderate antibacterial efficiency was observed in the ethanol and acetone extracts of Gloriosa superba L
\end{abstract}

Keywords: Endangered medicinal plant, Gloriosa superba L., antimicrobial activity, pathogenic microorganisms and disc diffusion method

\section{Introduction}

Plants have been a valuable source of natural products for maintaining human health especially, for the studies of natural therapies. Since ancient times, people have been exploring the nature for plants in the search of new drugs. Nature has been of material agents for thousands of years and an impressive number of modern drugs have been isolated from natural sources (Cragg and Newman, 2001 and Alam et al., 2009). This has resulted in the use of a large number of medicinal plants with curative properties that can treat various diseases and it is used in ayurvedic, allopathic and homeopathic treatment. According to the World Health Organization, more than $80 \%$ of the world population still relies on herbal medicines as their primary source of heath care. The popularity of using plants for therapeutic purposes has been intensified especially at the onset where traditional health care using traditional medicine is being promoted. Medicinal plants are being used by traditional healers either singly or in combination in the treatment of different types of diseases.Plants used for traditional medicine contain a wide range of substances that can be used to treat chronic as well as infectious diseases. Plants are used medicinally in different countries and are a source of many potent and powerful drugs (Srivastava et al., 1996, Bibitha et al., 2002 and Mahesh and Sathish, 2008). A wide range of medicinal plant parts is used for extract as raw drugs which possess varied medicinal properties and is reported to have minimal side effects (Maghrani et al., 2005). Gloriosa superba L.(Glory lily) is widely distributed in tropical and sub tropical parts of India including foothills of Himalayas (Kapoor, 2001). It is a national flower of Zimbabwe and also is a state flower of Tamil Nadu state of India.It is known by different names in India, such as Kalihari, Agnishikha, Languliata and Nangulika. The plant thrives from arid Bundelkhand to the humid Assam valley, India. The generic name Gloriosa means "full of glory" and superbameans "superb", alluding to the striking red and yellow flowers. Its extreme toxicity requires the most cautious of handling.

Gloriosa superb L.is an erect, herbaceous, climbing perennial growing between $3.5-6 \mathrm{~m}$ in length, usually trained at $1.5 \mathrm{~m}$ above the ground level. It is adapted to different soil texture and climatic variation. It occurs in thickets, forest edges and boundaries of cultivated areas in warm countries upto height of $253 \mathrm{~cm}$. (Neuwinger, 1994 and Ravindraade and Mahendra raj, 2009). Flowering is noticed from November to December (Swarnapriya et al., 1995). It is one of the most important medicinal plans of Asia and Africa (Sivakumar et al., 2000, Jana et al., 2011). It has been a well known plant in Indian Ayurveda as well as in pharmacological industries (Asolkar et al., 1992). Almost all parts of it find diverse medicinal usage (Kapoor, 2001). Its rhizomes used as a tonic, anti- periodic, anti- helminthic and also against snake bites and scorpion stings.

Gloriosa superb L. show many pharmacological properties like anti-inflammatory (Jomyet al., 2009), Antimicrobial (Hemaiswarya, 2009), Antithrombotic/Anticoagulant potential (Keeet al., 2008), Anticancer activity (Reuter, 2010), Snake bite potential (Haroon, 2008), Hapatoprotactive activity (Mohandass, 2011), Antioxidant activity (Amudha and Shanthi, 2011) and Anthelmintic Activity (Pawar, 2010) etc. Roots are acrid, anthelmintic, antipyretic, bitter, digestive, expectorant, highly poisonous and promoting expulsion of the placenta. Root paste is effective against paralysis, rheumatism, snake bite and insect bites (Chitra and Rajamani, 2009).

Environment is the interaction between man and the nature. Human beings are surrounded by plants, animals, and physical objects which are parts of our environment. Many medicinal plants are used to manufacture new antibiotics in pharmaceutical industry. These are resistance to

\section{Volume 6 Issue 12, December 2017}




\section{International Journal of Science and Research (IJSR) \\ ISSN (Online): 2319-7064}

Index Copernicus Value (2016): 79.57 | Impact Factor (2015): 6.391

microorganisms. In general, bacteria have the genetic ability to transmit and acquire resistance to drugs which are utilized as therapeutic agents.(Nascimento et al.,2000).

Antibiotics are one of our most important weapons in fighting bacterial infections and have greatly benefited the health related quality of human life since their introduction. However, over the past few decades these health benefits are under threat as many commonly used antibiotics have become less and less effective against certain illness not only because many of them produce toxic reactions but also due to investigate newer drugs with lesser resistance.

The search for antimicrobials of plant origin has been mainly stimulated by the fact that some of the major antibacterial agents have considerable drawbacks in terms of limited antimicrobial spectrum. Now-a-days multiple drug resistance has developed due to the indiscriminate use of commercial antimicrobial drugs commonly used in the treatment of infectious disease (Lakshmi Naidu et al., 2006). Resistance in bacteria is most prevalent like methicillin resistant Staphylococcus aureus (MRSA) has become a huge problem worldwide to treat nosocomial infections since 1990s (Lee $e t$ al., 2007).

The use of plant extract for medical treatments is enjoying great popularity since 1990 s when people realized that the effective life span of antibiotic is limited and over prescription and misuse of traditional antibiotics are causing microbial resistance (Cohen, 1992, Eisenberg et al., 1993 and Nascimento et al., 2000).

The antimicrobial activities of plant extracts may reside in a variety of different components, including aldehyde and phenolic compounds. Naturally occurring combinations of these compounds can be synergistic and often results in crude extracts having greater antimicrobial activity than the purified individual constituents (Delaquis, 2002 and Alam et al., 2009).Clinical microbiologists have great interest in screening of medicinal plants for antimicrobial activities and phytochemicals as potential new therapeutics (Nascimento et al., 2000). Hence the present investigation attempted the antimicrobial activity of Gloriosa superba L. whether it have high antimicrobial activity or not when compared to other medicinal plants.

\section{Materials and Methods}

\section{Sample Collection and Identification}

The study plant Gloriosa superb L. (leaf, stem, flower) was collected near Arasan Ganesan Polytechnique College, Sivakasi in Tamilnadu. The collected plant sample was identified in the Department of Botany, The Standard Fireworks Rajaratinam College for women, Sivakasi in Tamilnadu. The sample was stored in shadow places for further analysis.

\section{Preparation of Extracts}

The shadow dried Gloriosa superb L. samples (leaf, stem, flower) was powdered with the help of electronic blender. Twenty five gram of powdered plant material was taken in clean sterile Soxhlet apparatus and the extraction was done with $250 \mathrm{ml}$ of different solvents (low polar to high polar) like as hexane, butanol, ethanol, chloroform, water and acetone. Similarly, another 10 grams of Gloriosa superb L. powder was extracted with $100 \mathrm{ml}$ of acetone. After extraction the extracts were dried in room temperature until extract reach into solid form. From the solid extract suitable concentrations were made using Dimethyl sulfo-oxide (DMSO) for further analysis.

\section{Anti Microbial Activity-Antibacterial assay}

\section{Bacterial strains}

The bacterial strains were obtained from Joys Clinical laboratory in Nagercoil, Kanyakumari (District), Tamil Nadu. Three human bacterial pathogens were chosen for the present investigation. Purity of bacterial pathogens was screened using suitable biochemical tests before analysis. The pathogenic strains used in the present study were Escherichia coli, Pseudomonas aeruginosa, Bacillus sps. They were sub cultured in nutrient broth and incubated at $37^{\circ} \mathrm{C}$ for further analysis.

\section{Antibacterial screening}

The antibacterial activity was screened using disc diffusion method.

\section{Disc diffusion method}

Filter paper disc diffusion technique in agar was followed to determine antimicrobial activity by the procedure of Garg and Jain, 1998. Whatmann no.1 filter paper discs of 6-mm diameter, placed in dry Petri plates, were autoclaved. The test extracts in measured quantities were dissolved in minimum amount of acetone. Sterile filter paper No.1 discs were loaded with the extracts of Gloriosa superb L.(acetone, ethanol and water)using different solvents. The amount of extracts loaded in each disc was in the concentration viz., $25 \mu \mathrm{g} / \mathrm{ml}, 50 \mu \mathrm{g} / \mathrm{ml}, 75 \mu \mathrm{g} / \mathrm{ml}$ and $100 \mu \mathrm{g} / \mathrm{ml}$. Similarly discs were prepared for standard antibiotic streptomycin (w/v) and were impregnated in the filter paper discs in different concentrations $(50 \mu \mathrm{g} / \mathrm{ml})$.

The pathogenic strains were suspended with nutrient broth (High media) by transferring a loop full of $24 \mathrm{hrs}$ growth from agar slopes. The suspensions were vortexes and $0.1 \mathrm{ml}$ aliquots were spread over respective agar medium plates. The extracts and streptomycin loaded discs were then placed over the plates seeded with respective microorganisms. The plates were incubating at $37^{\circ} \mathrm{C}$ for $24 \mathrm{hrs}$. The antibacterial activity was determined by measuring the inhibition zone around the discs. The diameter of inhibition zones (including the diameter to the disc) was measured.

\section{Result and Discussion}

\section{Antimicrobial Activity}

\section{Screening of anti bacterial activity}

Antimicrobial screening of the leaf extracts of Gloriosa superba $\mathrm{L}$. were analysed in disc diffusion method. 


\section{International Journal of Science and Research (IJSR) \\ ISSN (Online): 2319-7064 \\ Index Copernicus Value (2016): 79.57 | Impact Factor (2015): 6.391}

\section{Disc diffusion method}

All solvent extracts of Gloriosa superb L. used in the present study exhibited degrees of antibacterial activity against tested pathogenic microorganisms Bacillus sp., Eschericia coli and Pseudomonas aeruginosa, when studied by the disc diffusion method. The acetone extract of Gloriosa superb L. was found to be effective against all tested micro organisms with inhibition zone ranging with an average of $1.0-2.9 \mathrm{~mm}$ in extracts prepared by mortar and pestle extractions (Table 1.1 and Plate $2.1-2.3$ ). When the result was compared with standard antibiotics streptomycin a moderate antibacterial efficiency was observed in the ethanol, acetone and water extracts of Gloriosa superb L.

Table 1.1: The Antibacterial Effect of Gloriosa Superba L. Using Acetone Extracts Against Human Pathogenic Bacterial Organisms in Disc Diffusion Method

Antimicrobial Activity of Acetone

\begin{tabular}{|c|c|c|c|c|c|c|c|c|c|c|}
\hline \multirow{3}{*}{ Solvent } & \multirow{3}{*}{$\begin{array}{l}\text { Conc. } \\
(\mu \mathrm{g} / \mathrm{ml})\end{array}$} & \multicolumn{9}{|c|}{ Diameter of inhibition (mm) } \\
\hline & & \multicolumn{3}{|c|}{ Bacillus sps. } & \multicolumn{3}{|c|}{ Eschericia coli. } & \multicolumn{3}{|c|}{ Pseudomonas aeruginosa } \\
\hline & & $\mathrm{S}$ & $\mathrm{L}$ & $\mathrm{F}$ & $\mathrm{S}$ & \begin{tabular}{|l|}
$\mathrm{L}$ \\
\end{tabular} & $\mathrm{F}$ & $\mathrm{S}$ & $\mathrm{L}$ & $\mathrm{F}$ \\
\hline \multirow[t]{4}{*}{ Acetone } & 25 & $0.8 \pm 0.08$ & $7 \pm 0.06$ & $0.8 \pm 0.08$ & $0.5 \pm \quad 0.06$ & $0.56 \pm 0.12$ & $0.5 \pm 0$. & $0.6 \pm 0.0$ & $0.6 \pm 0.22$ & $0.6 \pm 0.08$ \\
\hline & 50 & $1.7 \pm 0.08$ & $1.73 \pm 0.05$ & $1.63 \pm 0.05$ & $1.16 \pm 0.05$ & $1.26 \pm 0.05$ & $1.2 \pm 0.08$ & $1.2 \pm 0.08$ & $1.2 \pm 0.08$ & $1.2 \pm 0.08$ \\
\hline & 75 & $1.8 \pm 0.08$ & $1.8 \pm 0.08$ & $1.73 \pm 0.12$ & $1.46 \pm 0.05$ & $1.43 \pm 0.65$ & $1.43 \pm 0.12$ & $1.5 \pm 0.16$ & $1.5 \pm 0.08$ & $1.43 \pm 0.12$ \\
\hline & 100 & $2.3 \pm 0.16$ & $2.36 \pm 0.21$ & $2.4 \pm 0.08$ & $1.9 \pm 0.08$ & $1.86 \pm 0.12$ & $1.9 \pm 0.16$ & $1.83 \pm 0.12$ & $1.83 \pm 0.12$ & $1.86 \pm 0.17$ \\
\hline
\end{tabular}

Antimicrobial Activity of Water

\begin{tabular}{|c|c|c|c|c|c|c|c|c|c|c|}
\hline \multirow{2}{*}{ Solvent } & $\begin{array}{c}\text { Conc. } \\
\end{array}$ & \multicolumn{3}{|c|}{ Bacillus sps. } & \multicolumn{3}{c|}{ Eschericia coli. } & \multicolumn{3}{c|}{ Pseudomonas aeruginosa } \\
\cline { 2 - 11 } & $\mathrm{S}$ & $\mathrm{L}$ & $\mathrm{F}$ & $\mathrm{S}$ & $\mathrm{L}$ & $\mathrm{F}$ & $\mathrm{S}$ & $\mathrm{L}$ & $\mathrm{F}$ \\
\hline \multirow{3}{*}{ Water } & 25 & $0.36 \pm 0.09$ & $0.36 \pm 0.05$ & $1.4 \pm 0.17$ & $0.3 \pm 0.06$ & $0.3 \pm 0.08$ & $0.36+0.12$ & $0.4 \pm 0.08$ & $0.4 \pm 0.08$ & $0.46 \pm 0.21$ \\
\cline { 2 - 11 } & 50 & $0.8 \pm 0.08$ & $0.7 \pm 0.06$ & $0.8 \pm 0.08$ & $0.5 \pm 0.06$ & $0.56 \pm 0.12$ & $0.5 \pm 0.08$ & $0.6 \pm 0.08$ & $0.6 \pm 0.22$ & $0.6 \pm 0.08$ \\
\cline { 2 - 11 } & 75 & $1.7 \pm 0.08$ & $1.73 \pm 0.05$ & $1.63 \pm 0.05$ & $1.16 \pm 0.05$ & $1.26 \pm 0.05$ & $1.2 \pm 0.08$ & $1.2 \pm 0.08$ & $1.2 \pm 0.08$ & $1.2 \pm 0.08$ \\
\cline { 2 - 11 } & 100 & $1.8 \pm 0.08$ & $1.8 \pm 0.08$ & $1.73 \pm 0.12$ & $1.46 \pm 0.05$ & $1.43 \pm 0.64$ & $1.43 \pm 0.12$ & $1.5 \pm 0.16$ & $1.5 \pm 0.08$ & $1.43 \pm 0.12$ \\
\hline
\end{tabular}

Anti Microbial Activity of Ethanol

\begin{tabular}{|c|c|c|c|c|c|c|c|c|c|c|}
\hline \multirow{3}{*}{ Solvent } & \multirow{3}{*}{$\begin{array}{c}\text { Conc. } \\
(\mu \mathrm{g} / \mathrm{ml})\end{array}$} & \multicolumn{9}{|c|}{ Diameter of inhibition (mm) } \\
\hline & & \multicolumn{3}{|c|}{ Bacillus sps. } & \multicolumn{3}{|c|}{ Eschericia coli. } & \multicolumn{3}{|c|}{ Pseudomonas aeruginosa } \\
\hline & & $\mathrm{S}$ & $\mathrm{L}$ & $\mathrm{F}$ & $\underline{S}$ & $\mathrm{~L}$ & $\mathrm{~F}$ & $\mathrm{~S}$ & $\mathrm{~L}$ & $\mathrm{~F}$ \\
\hline & 25 & $1.7 \pm 0$ & $73 \pm 1$ & $1.63 \pm$ & & & & 08 & & $1.2 \pm 0.08$ \\
\hline & & & & & & & & & & \\
\hline & 75 & $2.3 \pm 0.16$ & $2.36 \pm 0.21$ & $2.4 \pm 0.08$ & $1.9 \pm 0.08$ & $1.86 \pm 0.12$ & $1.9 \pm 0.16$ & $1.83 \pm 0.12$ & $1.83 \pm 0.12$ & $1.86 \pm 0.17$ \\
\hline & 100 & $2.86 \pm 0.48$ & $2.8 \pm 0.08$ & $286+048$ & $24+008$ & $24+00$ & & $2.5 \pm 0.08$ & $1.83 \pm 0.12$ & $2.56 \pm 0.48$ \\
\hline
\end{tabular}

Anti Microbial Activity of Streptomycin

\begin{tabular}{|c|c|c|c|c|}
\hline \multirow{2}{*}{ Solvent } & \multirow{2}{*}{ Conc. $(\mu \mathrm{g} / \mathrm{ml})$} & \multicolumn{3}{|c|}{ Diameter of inhibition $(\mathrm{mm})$} \\
\cline { 3 - 5 } & & Bacillus & Eschericia coli. & Pseudomonas aeruginosa \\
\hline Streptomycin & 50 & $6.5 \pm 0.14$ & $7.3 \pm 0.17$ & $8.4 \pm 0.24$ \\
\hline
\end{tabular}

\section{References}

[1] Cragg, G.M. and Newman, D.J. 2001. Medicinal for the millennia. Ann.Ny Academic Science. 953: 3-25.

[2] Alam, M.T., Karim, M.M and Shakila, N. Khan. 2009. Antibacterial activity of different organic extracts of Achyranthes aspera and Cassia alata. Journal of Scientific Research. 1(2): 393-398.

[3] Bibitha, B., Jisha, V.K., Salitha, C.V., Mohan, S. and Valsa, A.K. 2002. Antibacterial activity of different plant extracts. Short Communication. Indian Journal of Microbiology. 42: 361-363.

[4] Srivastava, J., Lambert, J. and Vietmeyer, N. 1996.Medicinal plants: An expanding role in development. World Bank Technical Paper. No.320.

[5] Mahesh, B., and Sathish S. 2008. Antimicrobial activity of some important medicinal plant against plant and human pathogens. World Journal ofAgricultural Sciences. 4: 839-843.

[6] Maghrani, M., Zeggwah, N., Michel, J. and Eddouks M. 2005. Antihypertensive effect of Lepidium sativum in spontaneously hypertensive rats. Journal of Ethnopharmocology. 102(1-2): 193-197.

[7] Kapoor,L.D. 2001. Tradicinal uses of medicinal plant In: Ayurvedic medicinal plant.CRC press, New Delhi.

[8] Asolkar, L.V., Kakkar, K.K. and Chakre, O.J. 1992. Second supplement to glossary of indian medicinal plants with active principles part I (A-K). (1965-81). CSIR, New Delhi. 18-20.

[9] Neuwinger, H. D. 1994. African ethnobotany poisons and drugs chemistry.Journal of Biological Chemistry. 24: $213-214$.

Volume 6 Issue 12, December 2017 www.ijsr.net 